\title{
CHANGES IN MENTAL WELL-BEING OF ADULT POLES IN THE EARLY PERIOD OF THE COVID-19 PANDEMIC WITH REFERENCE TO THEIR OCCUPATIONAL ACTIVITY AND REMOTE WORK
}

\section{ZBIGNIEW WALDEMAR IZDEBSKI ${ }^{1}$ and JOANNA MAZUR ${ }^{2}$}

${ }^{1}$ University of Warsaw, Warsaw, Poland

Department of Biomedical Foundations of Development and Sexology, Faculty of Education

${ }^{2}$ University of Zielona Gora, Zielona Góra, Poland

Department of Humanization in Medicine and Sexology, Collegium Medicum

\begin{abstract}
Objectives: The present study focused on the relationship between occupational activity and mental health during the first COVID-19 lockdown. Material and Methods: At the turn of May and June 2020, an online survey was conducted on a representative sample of 3000 Poles (age: Me = 45 years). Working persons accounted for $52 \%$ of the respondents, while $38.1 \%$ were hired workers. Two standardized (0-100 pts) indices were defined. The level of mental health symptoms index (LMHSI) concerned the incidence of 4 problems within the past 2 months, whereas the change in mental health symptoms index (CMHSI) concerned the degree of mental health deterioration. Results: The mean value of LMHSI was 40.91 $(\mathrm{SD}=26.97)$, and that of CMHSI $60.51(\mathrm{SD}=23.97)$. In both cases, a worse assessment was obtained among women than among men. In the group of working respondents, the least advantageous results were found among those who worked casually or under a commission contract. Among the non-employed respondents, jobless persons and students were the group at risk. Remote work resulted in the deterioration of mental health in the light of CMHSI; however, a threat of changes in the professional situation affected LMHSI variability to the greatest extent The results of linear regression $\left(\mathrm{R}^{2}=0.339\right)$ suggest that the increase in the CMHSI score (adjusted for LMHSI) is independently influenced by female sex, university education, remote work and a threat of the worsening of employment terms. The analysis of the interaction effect showed a stronger impact of the last factor in the group of women $(\mathrm{p}=0.001)$. Conclusions: To conclude, COVID-19 restrictions were associated with a negative impact on mental health which should be analyzed in the occupational context. Int J Occup Med Environ Health. 2021;34(2):251-62
\end{abstract}

Key words:

online survey, employment status, COVID-19, remote work, mental health, change of employment terms

\section{INTRODUCTION}

The pandemic of COVID-19, which is an acute disease of the respiratory system caused by the SARS-CoV-2 virus, resulted in a worldwide crisis of a scale unparalleled since World War II. Poland was among the countries which quickly decided to close their borders, to introduce rigorous principles of quarantine, and to close educational facilities. The state of the epidemic was announced on March 1, 2020 [1], i.e., 16 days after the first case had been diagnosed in a patient from Zielona Góra. As early as in March,

Funding: this study was supported by University of Warsaw (grant No. III.3.2. entitled "Promotion of scientific research," grant manager: Zbigniew Waldemar Izdebski). Received: October 31, 2020. Accepted: January 29, 2021.

Corresponding author: Zbigniew Waldemar Izdebski, University of Warsaw, Department of Biomedical Foundations of Development and Sexology, Faculty of Education, Mokotowska 16/20,00-561 Warsaw, Poland (e-mail: zbigniew.izdebski@uw.edu.pl). 
the first significant imbalance on the labor market was observed as well as its orienteering towards the employers' market. Employees, who had dictated their terms, began fearing of losing their sources of income. In order to protect entrepreneurs and employees, changes in numerous provisions of law and financial instruments were proposed. These changes were jointly called the anti-crisis shield.

According to the data from Statistics Poland, the registered unemployment rate increased in the first months of the pandemic, from 5.4\% in March to $6.1 \%$ in June [2]. According to the National Official Business Register (REGON), the second quarter of 2020 brought a smaller number of registered business entities and a higher number of those which declared bankruptcy $(31.8 \%$ fewer and $10.8 \%$ more, respectively, as compared to the second quarter of 2019) [3]. The signs of recession have been shown by many other countries $[4,5]$.

In the initial phase of the pandemic, the restrictions concerning everyday life were thought to be of a temporary nature. Many institutions switched to remote work entirely or partly, prolonging the period of the changed terms of work still considered as temporary. Flexible terms of employment are not a new phenomenon but a system which has been operated by many companies for a number of years. In the face of the pandemic, many people had to switch to remote work, which they had not taken into consideration before, irrespective of their readiness to adopt that solution and the organizational conditions offered by the employer. This might result in a longer working time, and conflicts between family life and work; in consequence, it might adversely affect their mental health. As experts emphasize, the period of the pandemic affects the balance between work and family life, but it also creates many opportunities to improve relations within the family [6].

Since the outbreak of the COVID-19 pandemic, much has been told about the necessity to protect mental health of the society, including the groups particularly exposed to its worsening [7]. Attention has been focused on the elderly and those with co-existing diseases who feel more threatened as they are aware of the fact that if they become infected, their chances to survive are smaller [8]. Attention has also been paid to the people having a direct contact with the sick ones and those under obligatory quarantine [9]. Employers have tried to provide employees with extra forms of support and psychological assistance. To follow the mental condition of working Poles is a difficult task at the time of the pandemic. It may be expected that the condition was changing in subsequent months as was the course of the pandemic. The constant modification of the provisions of law and internal principles dictated by the employers might have been of some significance. In this context, the research is unique in its nature as it was carried out in the early months of the pandemic. In the future, its findings may be compared with further phases of the pandemic and the period following its end. This paper aims at analyzing the relationship between the occupational activity of Poles and the frequency of occurrence of the symptoms of worsened mental health during the first COVID-19 lockdown.

The following research questions were formulated:

- Did the mental well-being of adult Poles get worse within the first months of the COVID-19 pandemic?

- To what extent did the occupational status affect deterioration of the mental well-being?

- Have remote work and expected changes in the occupational status affected the mental health of working Poles?

\section{MATERIAL AND METHODS \\ Participants}

Data was collected within the framework of the project entitled "Poles' health and sexual life at the time of COVID-19," carried out at the Faculty of Education of the University of Warsaw and financed primarily by Polpharma. The survey was carried out online at the turn of May and June 2020. The respondents belonged to a na- 
tional sample of 100000 persons who took part in various online surveys organized by an external company (IQS Sp. z 0.o., Warsaw, Poland). A subsample representative of the country was drawn with quotas based on gender, age and the place of residence (province, size of town). The research was carried on until the target sample of 3000 persons aged $\geq 18$ was achieved. The initial questions in the online questionnaire included recruitment items to check the respondents' age and their readiness for answering the questions. The total number of people who were asked to complete the survey was not recorded, so the number of invited persons and the response rate are unknown.

The study obtained a positive opinion of the Scientific Research Ethics Committee of the University of Warsaw (No. 6/2020).

\section{The questionnaire}

The questionnaire included 16 thematic sections, and the time limit of $25 \mathrm{~min}$ was set for filling out. In the analysis, 23 questions were used. They concerned the following sections: health, demographic data, occupational status, and the current intimate relations.

\section{Dependent variables - mental health indices}

The following questions about 4 symptoms were analyzed, including 3 questions which had been many times used in the previous rounds of health surveys in Poland [10]:

- the feeling of loneliness and absence of close, friendly people in the immediate vicinity;

- periods of feeling low, experiencing depression, or poor well-being;

- periods of prolonged fatigue, weakness, somnolence, and concentration difficulty;

- tantrums, attacks of aggression, and frustration (a new symptom, added in 2020).

The first set of items concerned the occurrence of these symptoms within the past 2-3 months, and there were
6 categories of answers - from "very often" or "permanently" to "never" or "not at all." In the second set of items, the respondents were asked about changes in the frequency or intensity of their feelings and conditions as compared to the time before the COVID-19 pandemic. Here, there were 3 categories of answers, i.e., "they have increased," "they have remained unchanged," and "they have decreased." The questions about the change were asked only conditionally to those who had declared any problems.

On the basis of the foregoing groups of symptoms, 2 aggregate indices were defined. The first of them concerned the occurrence of mental health problems (the level of mental health symptoms index - LMHSI), and the second one referred to changes in the intensity of the problems (the change in mental health symptoms index - CMHSI). The answers were recoded so that higher scores would mean worse mental health. The first crude aggregate index ranged 0-30 pts, whereas the second one ranged 0-8 pts. Both indices were standardized to the range of 0-100 pts, according to the rules of standardization recommended by some authors [11]. Both scales were homogenous and Cronbach's $\alpha$ values confirmed their good reliability (0.823 and 0.844 , respectively).

\section{Independent variables}

The basic demographic and social features covered gender, age in years (calculated on the basis of the date of birth, and recoded into 4 groups), the level of education (12 categories recoded into 3 groups), and the size of the domicile ( 7 categories recoded into 4 groups).

The occupational activity was assessed with the following question: "Are you employed?" with 10 possible answers. Five answers concerned people who worked, divided into full-time work and work under a contract and other forms of employment (casual work, self-employment, a company owner, a farmer). The further 5 answers described the status of not working or studying people (students, 
pensioners and retired persons, the unemployed, housewives/househusbands).

Another question referred to remote work performed by the respondents or their partners, in the case of people who lived in a regular relationship (the answers were "yes" or "no"). Moreover, employed persons answered the questions pertaining to the expected risks of their professional situation. The following question was asked: "Have you already received any information from your employer about any changes in your professional situation within the coming 2-3 months?" The potential changes included an obligatory leave, the shortening of working time, the liquidation of social benefits, salary reduction, and the planned termination of employment.

\section{Statistical analysis}

With reference to LMHSI and CMHSI, their psychometric properties were examined via estimating Cronbach's $\alpha$ coefficient and examining the homogeneity of the summary scales with the principal component analysis.

The relationship of the categorized variables was examined with a $\chi^{2}$ test. The correlation of the continuous variables was examined with Spearman's @ coefficient.

The means of LMHSI and CMHSI were compared using the Mann-Whitney or Kruskall-Wallis nonparametric tests depending on the number of the groups to be analyzed.

As a part of the multivariate analysis, 4 linear regression models were estimated presenting the value and significance of the standardized $\beta$ parameter. More specifically, CMHSI was the dependent variable whereas LMHSI was the covariate together with other factors. The inclusion of the general level of a given phenomenon to the analyses of its dynamics is recommended and implemented in numerous elaborations although it is not classic longitudinal research [12]. The goodness-offit was examined with the $\mathrm{R}^{2}$ coefficient. The following models differed in the set of independent variables and the sample size because some information was available for selected persons (e.g., those who lived in a regular relationship).

The supplementary analysis sought the effects of interactions between the factors which conditioned CMHSI variability. Only those factors were taken into account which appeared significant in the previous step, and the analysis was limited to 2-way interactions.

All reported p-values were 2-tailed, and the values of $\leq 0.05$ were considered significant. The calculations were made using the IBM SPSS Statistics for Windows software v. 25.0 .

\section{RESULTS}

\section{The sample}

Table 1 presents the characteristics of the 3000 respondents who participated in the survey. The group was balanced in terms of gender (50.9\% of the respondents were women). The average age was 45.39 years $(\mathrm{SD}=16.21)$, and the median was close to the mean (45.0 years). The proportion of the employed persons was $52 \%$ of the respondents, including $38.1 \%$ of waged employees. The structure of the sample by domicile was similar to all-Poland data, with $40 \%$ of the sample represented by residents of rural areas. Persons with university education constituted $24.6 \%$ of the respondents. People living in a marital relationship accounted for $50.3 \%$ of the surveyed whereas $25.0 \%$ had been living in an informal relationship for $>6$ months.

\section{Assessment of mental health and symptoms of its deterioration}

The LMHSI value was estimated for $98.4 \%$ of the respondents ( $N=2951)$. Severe symptoms of mental health deterioration (i.e., "often" or "very often") occurred at the frequency from $14.7 \%$ (attacks of aggression) to $22.3 \%$ (periods of prolonged fatigue). The standardized average value of LMHSI was 40.91 (SD = 26.97). A higher intensity of the symptoms was found in the group of women than in men $(44.68 \pm 27.00$ vs. $37.00 \pm 26.40, p<0.001)$. The larg- 
est number of problems was reported by young people, mostly those who studied. While comparing the extreme age groups, i.e., 18-24 years and $>60$ years, a decrease in the average value of LMHSI of 16.6 pts was found. Thus, it may be stated that mental health improved in the subsequent age groups.

In the group who had experienced symptoms of mental health disorders, exacerbation within the period of the COVID-19 pandemic was found in 21.3\% (attacks of aggression) to $30.8 \%$ (tantrums), depending on the symptom. The proportion calculated for all the respondents may be a better measure of the burden with those problems among the population, and that figure was lower ranging 15.7-23.0\%. The standardized average value of CMHSI was $50.51(\mathrm{SD}=23.97)$. Its estimation was acquired for $60.8 \%$ of the respondents $(\mathrm{N}=1825)$, which arose from the definition of the index and the elimination of people with no reported problems. A higher intensity of the symptoms was found in the group of women than in men $(62.97 \pm 25.11$ vs. $57.63 \pm 22.24 ; p<0.001)$. In this case too, a deterioration of mental health was more often found in young people. While comparing the extreme age groups, i.e., 18-24 years and $>60$ years, the average value of CMHSI was lower by 8.8 pts. Starting with 45 years of age, the rate of the decrease in the CMHSI value was very small, i.e., it was not a systematic decrease as in the case of LMHSI. In addition, CMHSI was also found to negatively correlate with the chronological age, but not as strongly as LMHSI did $(\varrho=-0.121)$.

\section{Symptoms of deterioration of mental health} vs. occupational activity and remote work

Table 2 presents the mean values of those 2 indices with reference to the employment status. In both cases, the difference between 10 categories of occupational activity was statistically significant at the level of $p<0.001$. The least beneficial values of LMHSI were found in unemployed people and students, and the most beneficial ones - in retired and self-employed persons. Taking into
Table 1. Characteristics of the respondents taking part in the survey on the relationship between occupational activity and mental health during the first COVID-19 lockdown, May/June 2020, Poland

\begin{tabular}{|c|c|c|}
\hline \multirow[t]{2}{*}{ Variable } & \multicolumn{2}{|c|}{$\begin{array}{l}\text { Respondents } \\
(\mathrm{N}=3000)\end{array}$} \\
\hline & $\mathrm{n}$ & $\%$ \\
\hline \multicolumn{3}{|l|}{ Gender } \\
\hline male & 1472 & 49.1 \\
\hline female & 1528 & 50.9 \\
\hline \multicolumn{3}{|l|}{ Age } \\
\hline $18-24$ years & 407 & 13.6 \\
\hline $25-44$ years & 1091 & 36.4 \\
\hline $45-59$ years & 740 & 24.7 \\
\hline$\geq 60$ years & 762 & 25.4 \\
\hline \multicolumn{3}{|l|}{ Place of residence } \\
\hline rural area & 1207 & 40.2 \\
\hline \multicolumn{3}{|l|}{ town } \\
\hline$<100000$ inhabitants & 926 & 30.9 \\
\hline 100 000-500 000 inhabitants & 490 & 16.3 \\
\hline$>500000$ inhabitants & 377 & 12.6 \\
\hline \multicolumn{3}{|l|}{ Level of education } \\
\hline lower than secondary & 1217 & 40.6 \\
\hline secondary & 1046 & 34.9 \\
\hline higher or secondary & 737 & 24.6 \\
\hline \multicolumn{3}{|l|}{ Living in a regular relationship } \\
\hline none & 737 & 24.7 \\
\hline formal union (marriage) & 1503 & 50.3 \\
\hline informal union & 746 & 25.0 \\
\hline \multicolumn{3}{|l|}{ Employment status } \\
\hline hired worker & 1106 & 38.1 \\
\hline other forms of employment & 403 & 13.9 \\
\hline not working & 1395 & 48.0 \\
\hline
\end{tabular}

consideration only 3 categories of occupational activity (waged work, other forms of employment, and being non-employed), no differences were found in the level of this index ( $p=0.283)$. In the case of CNHSI, the conclusion on the differences between the groups changes. 
Table 2. The level of mental health symptoms index (LMHSI) and the change in mental health symptoms index (CMHSI) at the time of the pandemic by type of occupational activity, May/June 2020, Poland

\begin{tabular}{|c|c|c|}
\hline Occupational activity & $\begin{array}{c}\text { LMHSI } \\
(\mathrm{M} \pm \mathrm{SD})\end{array}$ & $\begin{array}{c}\text { CMHSI } \\
(\mathrm{M} \pm \mathrm{SD})\end{array}$ \\
\hline $\begin{array}{l}\text { Hired worker, employed at a company or enterprise on a full-time basis } \\
\text { or under a contract }(\mathrm{N}=1106)\end{array}$ & $39.65 \pm 26.25$ & $59.63 \pm 23.84$ \\
\hline Casual work under a commission contract or a contract for specific work $(\mathrm{N}=226)$ & $44.96 \pm 27.02$ & $65.10 \pm 25.46$ \\
\hline Self-employment $(\mathrm{N}=99)$ & $36.01 \pm 27.18$ & $64.18 \pm 23.36$ \\
\hline Company owner/co-owner $(\mathrm{N}=37)$ & $42.03 \pm 30.26$ & $62.50 \pm 21.65$ \\
\hline Farm owner $(\mathrm{N}=41)$ & $37.25 \pm 24.28$ & $55.50 \pm 19.79$ \\
\hline Student $(\mathrm{N}=171)$ & $47.87 \pm 27.95$ & $69.42 \pm 25.55$ \\
\hline Unemployed, currently non-employed person $(\mathrm{N}=255)$ & $48.52 \pm 27.36$ & $62.15 \pm 24.31$ \\
\hline Retired person $(\mathrm{N}=560)$ & $33.09 \pm 23.66$ & $58.06 \pm 21.50$ \\
\hline Pensioner $(\mathrm{N}=166)$ & $44.70 \pm 27.51$ & $61.08 \pm 19.77$ \\
\hline Housewife/househusband bringing up children $(\mathrm{N}=243)$ & $46.26 \pm 29.02$ & $57.62 \pm 25.70$ \\
\hline Refusal to answer $(\mathrm{N}=96)$ & $45.94 \pm 30.42$ & $53.51 \pm 27.83$ \\
\hline
\end{tabular}

LMHSI - 2951 valid cases; CMHSI - 1825 valid cases.

Apart from students, the value of the index was very high in the group of those who worked casually or were selfemployed (previously assessed well according to LMHSI). Conversely, the lowest index of changes in mental health was found in the owners of farms and housewives/househusbands. The difference between the 3 main groups of occupational activity is right on the threshold of statistical significance $(p=0.050)$. The lowest values of CMHSI occurred in the case of waged work $(\mathrm{M} \pm \mathrm{SD} 59.63 \pm 23.84)$, the highest one concerned other forms of employment $(\mathrm{M} \pm \mathrm{SD} 63.70 \pm 24.23)$ whereas the group of non-employed persons was placed in between $(\mathrm{M} \pm \mathrm{SD} 60.77 \pm 23.62)$.

Table 3 compares the values of LMHSI and CMHSI depending on remote work performed by the surveyed persons. Both the results referring to the components of this index are presented, as well as those referring to the aggregate score. Statistically significant differences were found only with reference to CMHSI. People who performed remote work were more exposed to the worsening of mental well-being.

\section{Symptoms of deterioration of mental health} and the risk of worsening of the professional situation In the surveyed group of adult Poles, 1509 persons answered the question pertaining to an expected change in their professional situation within the coming 2-3 months in the light of information acquired from their employer. The answers were provided also by some self-employed persons. Nearly half of the respondents did not expect any changes. The proportion of those who signaled a possible change was significantly smaller among those who worked full-time or under a contract as compared to other forms of employment (46.1\% vs. $61.8 \%, \mathrm{p}<0.001$ ).

The values of LMHSI and CMHSI grew significantly in the case of any threat of changes in the employment terms (Table 4). The LMHSI values grew significantly in the face of all the analyzed changes, with the highest increase caused by the risk of employment termination or the company winding-up. In the case of CMHSI, significant differences were found only with reference to any planned dismissal and reduction of salaries. The relationship with 
Table 3. Mental health symptoms and their changes at the time of the pandemic depending on the remote work status in the subsample of 1207 working respondents, May/June 2020, Poland

\begin{tabular}{|c|c|c|c|}
\hline \multirow[b]{2}{*}{ Variable } & \multicolumn{2}{|c|}{ Work status } & \multirow[b]{2}{*}{$\mathrm{p}^{*}$} \\
\hline & $\begin{array}{l}\text { remote work } \\
(\mathrm{N}=387)\end{array}$ & $\begin{array}{l}\text { traditional } \\
\text { workplace } \\
(\mathrm{N}=820)\end{array}$ & \\
\hline \multicolumn{4}{|l|}{ Very frequent or frequent partial symptoms of LMHSI ${ }^{a}$ in the past 2 months [\%] } \\
\hline the feeling of loneliness and absence of close, friendly people in the immediate vicinity & 15.7 & 15.8 & 0.947 \\
\hline periods of feeling low, experiencing depression, or poor well-being & 16.3 & 15.0 & 0.580 \\
\hline periods of prolonged fatigue, weakness, somnolence, and concentration difficulty & 20.1 & 19.6 & 0.846 \\
\hline tantrums, attacks of aggression, and frustration & 13.1 & 15.0 & 0.422 \\
\hline \multicolumn{4}{|l|}{$\begin{array}{l}\text { Worsening during the pandemic in the group having any problem referring to partial } \\
\text { symptoms of CMHSI }[\%]\end{array}$} \\
\hline the feeling of loneliness and absence of close, friendly people in the immediate vicinity & 36.6 & 21.9 & $<0.001$ \\
\hline periods of feeling low, experiencing depression, or poor well-being & 38.9 & 26.8 & $<0.001$ \\
\hline periods of prolonged fatigue, weakness, somnolence, and concentration difficulty & 31.6 & 25.4 & 0.055 \\
\hline tantrums, attacks of aggression, and frustration & 27.3 & 19.6 & 0.013 \\
\hline
\end{tabular}

CMHSI - change in mental health symptoms index; LMHSI - level of mental health symptoms index.

* Mann-Whitney U test and $\chi^{2}$ test, respectively.

${ }^{a}$ Standardized LMHSI: remote work $-\mathrm{M} \pm$ SD 38.43 \pm 26.75 , traditional workplace $-\mathrm{M} \pm \mathrm{SD} 38.26 \pm 26.00, \mathrm{p}=0.842$.

${ }^{\mathrm{b}}$ Standardized CMHSI: remote work $-\mathrm{M} \pm \mathrm{SD}$ 64.58 \pm 24.00 , traditional workplace $-\mathrm{M} \pm \mathrm{SD} 57.86 \pm 23.74, \mathrm{p}=0.001$.

the risk of an obligatory leave was close to the threshold of statistical significance $(\mathrm{p}=0.060)$.

\section{Multivariate analysis of the conditions}

\section{of deterioration of mental health}

Table 5 shows the results of multivariate linear regression models differing by a set of independent variables and the surveyed sample. The models explain 27.0-33.9\% of CMHSI variability. Domicile and living in a relationship did not affect CMHSI variability when adjusted to other factors. Neither was any relationship with age proven despite the foregoing clear trend concerning young people. The level of education remained an important predictor. Persons with university background achieved higher CMHSI values. Among the factors relating to work and affecting the index, the most important were the threat of a change in the professional situation and remote work performed by the respondent. In the subgroup of people living in a relationship, the inference referring to the influence of a partner's remote work was found to depend on the set of the analyzed factors (becoming weaker after including the level of education).

Some interesting conclusions were also drawn on the basis of the analysis of the 2-way interactions between the predictors of CMHSI variability, where the independent variables included gender, the level of education, remote work performed by the respondent, threats of changes in employment terms, and LMHSI as a covariate. One significant interaction was revealed between gender and a threat to the stability of employment terms $(\mathrm{p}=0.001)$. In the case of female workers, CMHSI increased on average by 7.84 pts in the face of work-related threats, while in the group of working men, there were no such changes. It appeared that, even when taking into consideration 
Table 4. The levels of 2 mental health indices at the time of the pandemic depending on expected changes in employment terms, in the subsample of 1509 working respondents, May/June 2020, Poland

\begin{tabular}{lcccccc}
\hline \multirow{2}{*}{\multicolumn{1}{c}{ Change in employment terms }} & \multicolumn{3}{c}{ LMHSI } & \multicolumn{3}{c}{ CMHSI } \\
\cline { 2 - 7 } & $\begin{array}{c}\text { expected } \\
\text { changes } \\
(\mathrm{M} \pm \mathrm{SD})\end{array}$ & $\begin{array}{c}\text { not expected } \\
\text { changes } \\
(\mathrm{M} \pm \mathrm{SD})\end{array}$ & $\mathrm{p}$ & $\begin{array}{c}\text { expected } \\
\text { changes } \\
(\mathrm{M} \pm \mathrm{SD})\end{array}$ & $\begin{array}{c}\text { not expected } \\
\text { changes } \\
(\mathrm{M} \pm \mathrm{SD})\end{array}$ & $\mathrm{p}$ \\
\hline Obligatory leave & $44.48 \pm 24.76$ & $39.53 \pm 26.76$ & 0.010 & $63.64 \pm 24.64$ & $60.18 \pm 23.86$ & 0.060 \\
Reduction of working time & $46.82 \pm 26.16$ & $39.04 \pm 26.46$ & $<0.001$ & $63.57 \pm 24.84$ & $60.11 \pm 23.33$ & 0.039 \\
Liquidation of social benefits & $49.64 \pm 26.37$ & $39.84 \pm 26.50$ & 0.007 & $64.42 \pm 27.14$ & $60.55 \pm 23.86$ & 0.237 \\
Salary reduction & $44.61 \pm 25.01$ & $39.34 \pm 26.76$ & 0.004 & $64.23 \pm 25.52$ & $59.95 \pm 23.61$ & 0.038 \\
Planned termination of employment & $58.64 \pm 25.39$ & $39.49 \pm 26.34$ & $<0.001$ & $69.69 \pm 27.43$ & $60.24 \pm 23.72$ & 0.005 \\
Liquidation or suspension of the company & $54.12 \pm 28.51$ & $39.87 \pm 26.42$ & 0.003 & $67.41 \pm 29.72$ & $60.50 \pm 23.79$ & 0.245 \\
\hline
\end{tabular}

Abbreviations as in Table 3.

other factors, women reacted more strongly than men with the worsening of their well-being to any expected changes in their professional situation.

\section{DISCUSSION}

The online survey carried out about 10-11 weeks after the COVID-19 epidemic had been announced by WHO included 3000 adult Poles. This paper is the first extensive publication which describes 1 part of this survey concerning changes in mental health, while leaving out the 3 other health dimensions (physical, social and sexual). The analyses were directed at assessing the relationship with occupational activity and performance of remote work. It was proven that there was a negative impact of remote work on the respondents' mental health in the initial period of the pandemic, and a still stronger adverse impact of the awareness of a threat to one's professional situation. The authors decided to show the findings referring to all the respondents, irrespective of their employment status. Thus, the effect of the analyses also focuses on a group of young people, students and unemployed persons where the deterioration of mental health was most vivid.

While planning this survey, an interesting methodological approach was applied as for the formulation of the items in the questionnaire. The functioning of the entire societies in the pandemic situation was a natural experiment impossible to foresee [13], so it is hard to acquire any data from the same persons concerning the period prior to, during and following the disappearance of, the pandemic (the latter has also proven impossible to be foreseen thus far). For this reason, the authors asked for a retrospection of the last 2-3 months and for an evaluation of the direction of changes (improvement, stabilization or worsening). The interpretation of the results was focused on the topics indicated as the main research questions, and the strengths and weaknesses of the research were continuously highlighted in the discussion.

The findings of the survey indicate that, in the initial period of the COVID-19 pandemic, a significant percentage of the respondents (ranging 15.3-23.0\%) declared the intensification of alarming symptoms, and they most frequently listed the symptoms defined as "despondence, depression, periods of malaise." Information from other countries confirms the worsening of mental health of various groups of people $[14,15]$. A typical phenomenon, also observed in this research, concerns the more frequent signals of mental problems reported by women than by men, which confirms the trend observed prior to the pandemic [16]. 
Table 5. Linear regression models* of the change in mental health symptoms index (CMHSI) against the selected factors (May/June 2020, Poland)

\begin{tabular}{|c|c|c|c|c|c|c|c|c|}
\hline \multirow{3}{*}{ Variable } & \multicolumn{8}{|c|}{ Linear regression model } \\
\hline & \multicolumn{2}{|c|}{ model 1} & \multicolumn{2}{|c|}{ model 2} & \multicolumn{2}{|c|}{ model 3} & \multicolumn{2}{|c|}{ model 4} \\
\hline & $\beta$ & $\mathrm{p}$ & $\beta$ & $\mathrm{p}$ & $\beta$ & $\mathrm{p}$ & $\beta$ & $\mathrm{p}$ \\
\hline Gender (male) & -0.061 & 0.003 & -0.098 & $<0.001$ & -0.093 & 0.001 & -0.081 & 0.013 \\
\hline Age & -0.010 & 0.650 & -0.001 & 0.983 & 0.004 & 0.874 & 0.009 & 0.769 \\
\hline Education higher than secondary & 0.098 & $<0.001$ & 0.127 & $<0.001$ & 0.104 & $<0.001$ & 0.091 & 0.007 \\
\hline Level of LMHSI & 0.505 & $<0.001$ & 0.514 & $<0.001$ & 0.516 & $<0.001$ & 0.495 & $<0.001$ \\
\hline Place of residence & 0.031 & 0.132 & 0.045 & 0.098 & 0.039 & 0.152 & 0.011 & 0.739 \\
\hline Living in a formal or informal union & 0.015 & 0.474 & -0.019 & 0.499 & -0.017 & 0.533 & - & - \\
\hline Working & -0.039 & 0.062 & - & - & - & - & - & - \\
\hline Risk of change in employment conditions & - & - & 0.096 & $<0.001$ & 0.097 & $<0.001$ & 0.102 & 0.001 \\
\hline Remote work performed by the respondent & - & - & - & - & 0.065 & 0.025 & 0.074 & 0.026 \\
\hline Remote work performed by his or her partner & - & - & - & - & - & - & 0.056 & 0.076 \\
\hline $\mathrm{R}^{2}$ & 0.270 & & 0.335 & & 0.339 & & 0.308 & \\
\hline
\end{tabular}

$\beta$-standardized parameter.

* Each model was estimated for a different number of cases because of the lack of relevant data for the subgroups of respondents (working remotely, having a partner): model $1-\mathrm{N}=1817$, model $2-\mathrm{N}=932$, model $3-\mathrm{N}=932$, model $4-\mathrm{N}=740$.

With reference to the second research question, it was shown that the worsening of mental health (expressed as CMHSI) was most strongly visible in the group of respondents whose employment status was other than waged work. Among the non-employed respondents, jobless persons assessed the change in their mental health as worse compared to other groups. This was quite expectable as unemployment, and in particular long-term unemployment, may seriously affect both physical and mental health of unemployed persons [17]. The influence of unemployment on health at the time of economic crisis was analyzed relatively recently in the context of the global recession of the early 21st century [18]. In these analyses, in the group of employed persons, the highest values of CMHSI were achieved by those who worked casually without a secured income.

It is also worth emphasizing that, with reference to CMHSI, the least beneficial value was achieved by students. This coincides with the analyses by respondents' age. It is assumed that previously experienced stressful situations made the el- derly more resistant, and they coped with the psychical hardships of the imposed restrictions better than younger persons. As compared with the previous Polish surveys of 2017, the shape of the relationship between age and mental health changed profoundly [10], which may be typical of crisis situations only. On the basis of the gathered data, it is difficult to acquire a full image of the economic situation of young adults as one category of employment prevailed in the declaration. Worldwide reports do not lead to any unambiguous inference relating to the comparison of age groups with reference to mental health in the pandemic period. A similar relationship expressed as a decrease in depression symptoms along with age at the time of the COVID-19 pandemic was found in Canadian research [19]. While analyzing the employment status, the authors used an extensive classification of 10 economic groups. Their comparison is burdened with incompatibility with the specificity of a crisis situation. Thus, it is worth turning attention to alternative classifications, more and more 
often quoted in literature, e.g., the division proposed by Reich [20,21]. He assumed the existence of 4 emerging groups, adapted to elaborations concerning COVID-19, which, however, do not depict the entire population. The groups are referred to as: the remotes (those who can work remotely), the essentials (representatives of professions of key importance for combating the pandemic), the unpaid (persons most exposed to the worsening of their professional situation due to loss of jobs or salary reduction) and the forgotten (persons who, due to their living conditions, cannot maintain the social distance, e.g., people living in immigrant camps). In the course of this survey, the respondents were not asked precisely about the performed job but an element of assessing the threat of a change in the professional situation was introduced, which is closest to the group of the unpaid, and a question was asked about remote work to identify people from the group of the remotes.

The disadvantage of the research project may be the fact that no attention was paid to the group of the essentials, i.e., those who combat the pandemic on the front line, including non-medical employees [22]. A large part of the elaborations related to the impact of the pandemic on mental health is limited to medical staff [23-25].

With reference to the third research question, persons who work remotely should be discussed to a wider extent. As compared to those who worked away from home, they more often signaled intensification of the symptoms of mental health disorders. The greatest differences $(14.7 \%$ more among those who reported a given symptom) were found with reference to "the feeling of loneliness and absence of close, friendly persons in the immediate vicinity." Australian research has shown that social isolation was the restriction most difficult to bear [26].

While analyzing the professional situation, a lot of attention was paid to its prognosis in the respondents' opinions. Mental health worsened most among the employed persons who faced a real risk of losing their jobs or a threat that their company would be wound up (suspended). The view of a change in the professional situation affected the psyche of women to a greater extent than in men. Despite the fact that, from the medical point of view, COVID-19 brings a greater hazard for men, in the social dimension women pay a high price [27]. As the British Sunday newspaper The Observer has put it, burdening women with housework together with professional duties brought them closer to the situation of housewives of 70 years ago [28].

As already stated, the research project itself, as this part of the analyses, has several advantages but also some limitations. Undoubtedly, the advantages include a large representative sample and the application of previously tested research tools, as well as the relationship with periodically repeated health surveys [10]. Apart from those specified above, the limitations arise from a small set of the analyzed factors. The unique nature of this research is expressed by the time of the survey which reduces the risk of recall bias. Should the topic be examined later at the constantly changing conditions and accumulated experiences of the past months, the survey would not provide such a reliable assessment of the response to the initial experiences related to the pandemic.

\section{CONCLUSIONS}

To conclude, COVID-19 restrictions were associated with a negative impact on mental health which should be analyzed in the occupational context. The factors profoundly related to the deterioration of mental health appeared to be: female gender, remote work and a having real vision of the worsening of one's professional situation. The findings are an important point of reference for surveys to be conducted at the future stages of the pandemic and after its disappearance.

\section{REFERENCES}

1. [Regulation of the Minister of Health of 20 March 2020 on the declaration of an epidemic in the territory of the Republic of Poland. J Laws 2020, item 491]. Polish. 
2. Ministry of Health [Internet]. Warsaw: The Ministry; 2020 [cited 2020 Oct 12]. [Registered unemployment rate in 19902020]. Available from: https://stat.gov.pl/obszary-tematyczne/ rynek-pracy/bezrobocie-rejestrowane/stopa-bezrobociarejestrowanego-w-latach-1990-2020,4,1.html. Polish.

3. Ministry of Health [Internet]. Warsaw: The Ministry; 2020 [cited 2020 Oct 12]. [Registrations and bankruptcies of shares in 2nd albums of 2020]. Available from: https://stat.gov.pl/files/ gfx/portalinformacyjny/pl/defaultaktualnosci/5502/29/6/1/ rejestracje_i_upadlosci_podmiotow_gospodarczych_w_drugim_kwartale_2020.pdf. Polish.

4. Kousi T, Mitsi LC, Simos J. The Early Stage of COVID-19 Outbreak in Greece: A Review of the National Response and the Socioeconomic Impact. IJERPH. 2021;18(1):322, https:// doi.org/10.3390/ijerph18010322.

5. VoxEU CEPR [Internet]. London: Centre for Economic Policy Research; 2020 [cited 2020 Oct 11]. Helsinki Graduate School of Economics Situation Room. Real-time economic analysis of the COVID-19 crisis: Lessons from Finland. Available from: https://voxeu.org/article/real-time-economicanalysis-covid-19-crisis-lessons-finland.

6. Cluver L, Lachman JM, Sherr L, Wessels I, Krug E, Rakotomalal S, et al. Parenting in a time of COVID-19. Lancet. 2020;395(10231):e64, https://doi.org/10.1016/S0140-6736(20) 30736-4.

7. Holmes EA, O’Connor RC, Perry VH, Tracey I, Wessely S, Arseneault L, et al. Multidisciplinary research priorities for the COVID-19 pandemic: A call for action for mental health science. Lancet Psychiatry. 2020;7:547-60.

8. Imam Z, Odish F, Gill I, O'Connor D, Armstrong J, Vanood A, et al. Older age and comorbidity are independent mortality predictors in a large cohort of 1305 COVID-19 patients in Michigan, United States. J Intern Med. 2020;288(4):469-76, https://doi.org/10.1111/joim.13119.

9. Hossain MM, Sultana A, Purohit N. Mental health outcomes of quarantine and isolation for infection prevention: A systematic umbrella review of the global evidence. Epidemiol Health. 2020;42:e2020038.
10. Izdebski I. [Sexual health and life of Poles aged 18-49 in 2017. Research study in the context of changes since 1997]. Warsaw: Warsaw University Press; 2020. Polish.

11. Šmigelskas K. Score-to-percent coefficient: Use and potential in health sciences and psychology. Global J Res Anal. 2018;7(1):341-3.

12. SAS Global Forum [Internet]. Paper 1798-2014 [cited 2020 Oct 9]. Hyer JM, Waller JL. Comparison of Five Analytic Techniques for Two-Group Pre-Post Repeated Measures Designs Using SAS. Available from: http://support.sas.com/ resources/papers/proceedings14/1798-2014.pdf.

13. Islam N, Sharp SJ, Chowell G, Shabnam S, Kawachi I, Lacey $\mathrm{B}$, et al. Physical distancing interventions and incidence of coronavirus disease 2019: natural experiment in 149 countries. BMJ. 2020;370:m2743, https://doi.org/10.1136/bmj.m2743.

14. Gualano MR, Lo Moro G, Voglino G, Bert F, Siliquini R. Effects of Covid-19 Lockdown on Mental Health and Sleep Disturbances in Italy. IJERPH. 2020;17:4779, https://doi.org/ 10.3390/ijerph17134779.

15. Wang C, Pan R, Wan X, Tan Y, Xu L, Ho CS, et al. Immediate psychological responses and associated factors during the initial stage of the 2019 coronavirus disease (COVID-19) epidemic among the general population in China. IJERPH. 2020;17(5):1729, https://doi.org/10.3390/ijerph17051729.

16. Gurvich CT, Thomas N, Hudaib, AR, Sood L, Fabiato K, Sutton K, et al. Coping styles and mental health in response to societal changes during the COVID-19 pandemic. Int J Soc Psychiatr. https://doi.org/10.1177/0020764020961790 [in press].

17. López del Amo González M, Benítez V, Martín-Martín JJ. Long term unemployment, income, poverty, and social public expenditure, and their relationship with self-perceived health in Spain (2007-2011). BMC Public Health. 2018;18:114, https://doi.org/10.1186/s12889-017-5004-2.

18. Brenner MH, Andreeva E, Theorell T, Goldberg M, Westerlund $\mathrm{H}$, Leineweber $\mathrm{C}$, et al. Organizational downsizing and depressive symptoms in the European recession: The experience of workers in France, Hungary, Sweden and the 
United Kingdom. PLoS ONE. 2014;9(5):e97063, https://doi. org/10.1371/journal.pone.0097063.

19. Nwachukwu I, Nkire N, Shalaby R, Hrabok M, Vuong W, Gusnowski A, et al. COVID-19 Pandemic: Age-Related Differences in Measures of Stress, Anxiety and Depression in Canada. IJERPH. 2020;17:6366, https://doi.org/10.3390/ ijerph17176366.

20. The Guardian [Internet]. London: Guardian Media Group 2020 [cited 2020 Oct 11]. Reich R. Coronavirus Outbreak Covid-19 Pandemic Shines a Light on a New Kind of Class Divide and its Inequalities. Available from: https://www.theguardian. com/commentisfree/2020/apr/25/covid19-pandemic-shines-alight-on-a-new-kind-of-class-divide-and-its-inequalities.

21. Kim YJ, Kang SW. The Quality of Life, Psychological Health, and Occupational Calling of Korean Workers: Differences by the New Classes of Occupation Emerging Amid the COVID-19 Pandemic. IJERPH. 2020;17:5689, https:// doi.org/10.3390/ijerph17165689.

22. Ruiz-Frutos C, Ortega-Moreno M, Allande-Cusso R, Dominguez-Salas S, Dias A, Gomez-Salgado J. Health-related factors of psychological distress during the COVID-19 pandemic among non-health workers in Spain. Safety Sci. 2021;133:104996 https://doi.org/10.1016/j.ssci.2020.104996.

23. Da Silva FCT, Neto MLR. Psychiatric symptomatology associated with depression, anxiety, distress, and insomnia in health professionals working in patients affected by
COVID-19: A systematic review with meta-analysis. Prog Neuropsychopharmacol Biol Psychiatry. 2021;104:110057, https://doi.org/10.1016/j.pnpbp.2020.110057.

24. Barello S, Falco-Pegueroles A, Rosa D, Tolotti A, Graffigna $G$, Bonetti $L$. The psychosocial impact of flu influenza pandemics on healthcare workers and lessons learnt for the COVID-19 emergency: a rapid review. IJPH. 2020;65(7):1205-6, https://doi.org/10.1007/s00038-020-01463-7.

25. Pappa S, Ntella V, Giannakas T, Giannakoulis VG, Papoutsi E, Katsaounou P. Prevalence of depression, anxiety, and insomnia among healthcare workers during the COVID-19 pandemic: A systematic review and meta-analysis. Brain Behav Immun. 2020;88:901-7, https://doi.org/10.1016/j.bbi. 2020.05.026.

26. Beck MJ, Hensher DA. Insights into the impact of COVID-19 on household travel and activities in Australia The early days under restrictions. Transp Policy. 2020;96:7693, https://doi.org/10.1016/j.tranpol.2020.07.001.

27. Mantovani A, Dalbeni A, Beatrice G. Coronavirus disease 2019 (COVID-19): we don't leave women alone. IJPH. 2020; 65:235-6.

28. The Guardian [Internet]. Ferguson D. "I feel like a 1950s housewife": How lockdown has exposed the gender divide. [cited 2020 Oct 12]. Available from: https://www.theguardian.com/world/2020/may/03/i-feel-like-a-1950s-housewife-how-lockdown-has-exposed-the-gender-divide

This work is available in Open Access model and licensed under a Creative Commons Attribution-NonCommercial 3.0 Poland License - http://creativecommons.org/ licenses/by-nc/3.0/pl/deed.en. 